\title{
A Pharmacist Telephone Intervention to Identify Adherence Barriers and Improve Adherence Among Nonadherent Patients with Comorbid Hypertension and Diabetes in a Medicare Advantage Plan
}

\author{
Susan M. Abughosh, PhD; Xin Wang, MS; Omar Serna, PharmD, BCACP; Chris Henges, PharmD; \\ Santhi Masilamani, PharmD, CDE, MBA; Ekere James Essien, MD, DrPH; \\ Nancy Chung, PharmD, BCACP; and Marc Fleming, PhD
}

\section{ABSTRACT}

BACKGROUND: Patients with comorbid hypertension (HTN) and diabetes mellitus (DM) are at a high risk of developing macrovascular and microvascular complications of DM. Controlling high blood pressure can greatly reduce these complications. Angiotensin-converting enzyme inhibitors (ACEls) or angiotensin II receptor blockers (ARBs) are recommended for patients with both DM and HTN by the American Diabetes Association guidelines, and their benefit and efficacy in reducing macrovascular and microvascular complications of DM have been well documented. Poor adherence, however, remains a significant barrier to achieving full effectiveness and optimal outcomes.

OBJECTIVE: To examine the effect of a brief pharmacist telephone intervention in identifying adherence barriers and improving adherence to ACEI/ARB medications among nonadherent patients with comorbid HTN and DM who are enrolled in a Medicare Advantage plan.

METHODS: Cigna-HealthSpring's medical claims data was used to identify patients with HTN and DM diagnoses by using ICD-9-CM codes 401 and 250, and at least 2 fills for ACEls or ARBs between January 2013 and October 2013. Patients who failed to refill their medication for more than 1 day and had a proportion of days covered $(\mathrm{PDC})<0.8$ were considered nonadherent and were contacted by a pharmacist by phone to identify adherence barriers. Two outcome variables were evaluated: The first was adherence to ACEIs/ARBs, defined as PDC during the 6 months following the phone call intervention. The second outcome variable was a categorical outcome of discontinuation versus continuation. Discontinuation was defined as not using ACEIs/ARBs during the 6-month post-intervention period. Patients who disenrolled from the plan in 2014 or were switched to another medication commonly used for treating DM and HTN were excluded from further analysis. Descriptive statistics were conducted to assess the frequency distribution of sample demographic characteristics at baseline. Multiple linear regression was conducted to assess the intervention effect on adherence during the 6 months post-intervention using the first outcome of post-intervention PDC, adjusting for baseline PDC and other covariates. Logistic regression was performed to assess the association between medication discontinuation and other baseline characteristics using the second outcome of discontinuation. Other control variables in the models included demographics (age, sex, language), physician specialty (primary care vs. specialist), health plan (low-income subsidy vs. other), Centers for Medicare \& Medicaid risk score, Charlson Comorbidity Index, and number of distinct medications.
RESULTS: In total, 186 hypertensive diabetic patients, nonadherent to ACEls/ARBs ( $\mathrm{PDC}<0.8$ ), were included in the study. Of the 186 patients, 87 received the pharmacist phone call intervention. Among these patients, forgetfulness (25.29\%) and doctor issues, such as having difficulty scheduling appointments (16.79\%), were the most commonly reported barriers. After excluding those who switched from ACEls/ARBs to another medication, 157 patients were included in the logistic regression model. Of those, 131 had continued using ACEIs/ARBs and were included in the linear regression model. The mean $( \pm \mathrm{SD})$ post-intervention PDC for the intervention group was $0.58( \pm 0.26)$ and for the control group $0.29( \pm 0.17)$. Intervention was a significant predictor of better adherence in the linear regression model after adjusting all the other baseline covariates $(\beta=0.3182,95 \%$ $\mathrm{Cl}=0.19-0.38, P<0.001$ ). Other covariates were not significantly associated with better adherence. In the logistic regression model (discontinuation: 26 [yes]/131 [no]) for predicting medication discontinuation, patients who received intervention were more likely to continue using ACEls/ARBs $(0 \mathrm{R}=3.56,95 \% \mathrm{Cl}=1.06-11.86)$, and those with a higher comorbidity index were less likely to continue using them $(0 \mathrm{R}=0.72,95 \% \mathrm{Cl}=0.53-0.99)$.

CONCLUSIONS: The brief pharmacist telephone intervention resulted in significantly better PDCs during the 6 months following the intervention as well as lower discontinuation rates among a group of nonadherent patients with comorbid HTN and DM. The overall PDC rates in both the intervention and control groups were still lower than the recommended $80 \%$. Improving adherence to clinically meaningful values may require more than a brief pharmacist phone call. Incorporating motivational interviewing techniques with follow-up calls to address adherence barriers may be more influential in forming sustainable behavioral change and enhancing medication adherence.

J Manag Care Spec Pharm. 2016;22(1):63-73

Copyright $\odot 2016$, Academy of Managed Care Pharmacy. All rights reserved.

\section{What is already known about this subject}

Telephone interventions have been shown to improve adherence among patients with diabetes mellitus (DM).

Studies suggest that intensified care, including intensified patient counseling, education, and training programs, from a pharmacist can improve medication adherence among patients with DM and hypertension (HTN). 


\section{What this study adds}

- Among a group of nonadherent elderly patients with comorbid HTN and DM in a Medicare Advantage plan, a brief telephone intervention by a pharmacist resulted in significantly better proportion of days covered (PDC) rates and lower discontinuation of angiotensin-converting enzyme inhibitors/angiotensin II receptor blockers during the 6 months following the intervention.

The overall PDC rates in the intervention and control groups were still lower than the recommended $80 \%$. Improving adherence to clinically meaningful values may require more than a brief pharmacist phone call.

This study found forgetfulness (25.29\%) and doctor issues, such as having difficulty scheduling appointments (16.79\%), were the most commonly reported barriers. Incorporating motivational interviewing techniques with follow-up calls to address these adherence barriers may be more influential in forming a sustainable behavioral change and enhancing medication adherence.

$\mathrm{M}$ edication adherence is the essential link between prescribing a medication and treatment success and is crucial in achieving maximum effectiveness for favorable outcomes of prescribed regimens. ${ }^{1-3}$ Adherence is defined as the extent to which a patient takes medications as they are prescribed and recommended by a health care provider. ${ }^{3-5}$ Literature reports that $20 \%-50 \%$ of patients do not adhere to their prescribed regimens, and the problem is more prominent in older adults, with $40 \%-86 \%$ of elderly patients reported to be nonadherent, ${ }^{1,3,6}$ as they often use more medications, experience a higher number of illnesses, and are at risk of age-related cognitive decline. ${ }^{2,7}$

In the United States, 33\%-69\% of all medication-related hospital admissions are attributable to poor medication adherence, at an annual cost of $\$ 100$ billion. ${ }^{3,5}$ With more than 32 million Americans receiving prescription drug benefits from Medicare (through Medicare Part D or Medicare Advantage), ${ }^{8}$ research aimed at identifying barriers to adherence in this population and developing impactful interventions is greatly needed.

Diabetes mellitus (DM) and hypertension (HTN) are independent risk factors for cardiovascular $(\mathrm{CV})$ diseases and major public health issues in the United States. ${ }^{9,10}$ In 2050, an estimated 50 million Americans will have DM and 100 million will have HTN. ${ }^{9}$ The conditions frequently coexist, with 70\%-80\% of DM patients also having HTN. ${ }^{9,11}$ Known as the deadly duet, the combination significantly increases the risk of macrovascular (including diseases such as stroke, coronary artery disease, and peripheral arterial disease) and microvascular (diabetic nephropathy, neuropathy, and retinopathy) DM complications. ${ }^{10}$ Controlling high blood pressure (BP) can greatly reduce these complications, including the CV risk, ${ }^{10-14}$ which accounts for $50 \%-80 \%$ of diabetic fatalities. ${ }^{9,10,13,15,16}$
American Diabetes Association guidelines ${ }^{10,17-19}$ recommend angiotensin-converting enzyme inhibitors (ACEIs)/angiotensin II receptor blockers (ARBs) in the hypertensive regimen for patients with both DM and HTN, and their benefit and efficacy in reducing macrovascular and microvascular complications of DM have been well documented. ${ }^{10,19-22}$ Poor adherence, however, remains a significant barrier to achieving full effectiveness, with reported nonadherence rates to antihypertensive therapy among DM patients of $20 \%-23 \%, 16,23,24$ and has been linked to uncontrolled $\mathrm{BP}^{13,16,24-26}$ and $\mathrm{CV}$ morbidity and mortality among DM patients with HTN. 16,24,27-29

Telephone interventions have been shown to improve care among DM patients, ${ }^{30-33}$ and intensified care such as intensified patient counseling, education, and training programs from a pharmacist have demonstrated benefits in improving adherence among patients with $\mathrm{DM}^{34-38}$ and $\mathrm{HTN},{ }^{39-43}$ as well as among older adults in general. ${ }^{44}$

Pharmacist-led interventions have also been shown to improve BP control among patients with HTN and DM. ${ }^{45,46}$ Pharmacists have also been influential in improving CV risk factors among older adult patients in general ${ }^{47}$ and DM patients in particular. ${ }^{48}$

The objective of this research was to examine the effect of a brief pharmacist telephone intervention in identifying adherence barriers and improving adherence to ACEI/ARB medications among nonadherent patients with comorbid HTN and DM who are enrolled in a Medicare Advantage plan.

\section{Methods}

\section{Study Design, Data Sources, and Population}

A retrospective cohort study was conducted using CignaHealthSpring's medical claims database. The protocol was reviewed and approved by the relevant Committee for the Protection of Human Subjects at the University of Houston.

The study population consisted of continuously enrolled members of the Medicare prescription drug plan in Texas from January 2013 to June 2014.

\section{Data Files}

Several computerized data files, including membership file, member summary file, institutional claims file, professional claims file, and pharmacy file, were used. Membership and member summary files include demographic, severity scores, and cost data for beneficiaries for each year. Institutional claims file include information on all inpatient claims. The files contain diagnostic information in the form of International Classification of Diseases, Ninth Revision, Clinical Modification (ICD-9-CM) codes, and procedure information in the form of Current Procedural Terminology codes. Professional claims contain information on all outpatient encounters. Pharmacy files contain Part D pharmacy data provided by a pharmacy benefits manager. 
Inclusion Criteria. Patients who had a diagnosis of HTN and DM identified by ICD-9-CM codes 401 and 250 with at least 2 fills for ACEI or ARB therapy between January 2013 and October 2013 were included. Individual medications were identified and categorized as ACEIs/ARBs. Nonadherent patients between October 1, 2013, and December 31, 2013, were initially selected from the "failure to refill" report that is updated biweekly by the health plan to identify members of the plan who have failed to pick up their prescription medications for more than 1 day. Members also had to have a proportion of days covered (PDC) $<80 \%$ for their ACEI/ARB medication before the intervention was included. The date of receiving the phone call intervention was defined as the index date, and the 6-month follow-up period was defined as the post-intervention period.

\section{Intervention}

A brief telephone intervention by a pharmacist was carried out among 87 patients randomly selected from the patients identified who were nonadherent to their ACEI/ARB medication between October 1, 2013, and December 31, 2013. Patients who were not contacted were in the comparator group. PDC is frequently used as a measure of patient adherence, ${ }^{49}$ and $80 \%$ is the most commonly used cut-off point generally considered acceptable. ${ }^{5,24}$

A pharmacist at the health plan contacted these patients by phone to identify potential adherence barriers. The pharmacist followed a standardized template in order to guide the conversation with the subject, provided appropriate education, and tried to address the patient concerns. The approved script was tailored to fit the subjects' responses and included an introduction, an alert to the patients that their medication was past due for a refill, and targeted questions to identify barriers to medication adherence, which were to be followed up with individualized recommendations to deal with any issues identified (see Appendix for actual script). The discussion length varied by subject need and clinical judgment by the pharmacist, with most conversations lasting about 3-5 minutes. The pharmacist also contacted the patients' physicians or pharmacies when possible to resolve the issues discussed with the patients. The barriers identified by the pharmacist during the phone call were documented.

\section{Outcome Measures}

The primary outcome was adherence to ACEIs and ARBs, defined as PDC during the 6 months following the implementation of the phone call intervention. Patients who disenrolled from the plan in 2014 or were switched to a diuretic or other medication were excluded from further analysis. PDC represents the proportion of days during the measurement period that are covered by prescription claims for ACEIs or ARBs. An index date defined as the intervention call date was identified.
The PDC during the 6 months following the index date was calculated by dividing the total number of days covered by ACEIs or ARBs by the total number of days in the measurement period (180 days). ${ }^{50}$ If there was more than 1 prescription for an ACEI or ARB covering the same calendar day, the day was only counted once. If prescription fills for the same drug overlapped, the prescription start dates were adjusted to be the day after the previous fill had ended. Days supply that extended beyond the measurement period was truncated at 180 days. For the controls, an index date of October 1, 2013, was used, as it is the start date of the intervention. Baseline medication adherence was calculated as the PDC during the 6 months before the index date. Baseline and post-intervention PDC were calculated for the intervention and control groups, respectively.

Discontinuation was defined as not using any ACEIs/ARBs during the 6-month post-intervention period, excluding those who were switched to other drug classes used to treat DM and HTN. A switch was defined as using ACEIs/ARBs during the baseline period and using other drug classes to treat DM and HTN instead of ACEIs/ARBs, including calcium channel blockers, diuretics, beta-blockers, and alpha-blockers.

\section{Statistical Analysis}

Descriptive analyses were conducted to assess the frequency distribution of sample demographic characteristics at baseline. Student t-tests were conducted for continuous variables to assess the differences in mean values across the intervention and control groups. Chi-square tests were performed to assess the group difference for categorical variables across intervention and control groups. Bivariate analysis was conducted to assess the unadjusted association between the post-intervention PDC and each independent variable. Multiple linear regression was conducted to assess the intervention effect on adherence during the 6-month post-intervention period, adjusting for baseline PDC and other covariates. The outcome variable was the 6-month post-intervention PDC in the linear regression model. Logistic regression was performed to assess the association between medication discontinuation and other baseline characteristics. The outcome variable was categorized as discontinuation (yes/no) in the logistic model. Other control variables included demographics (age, sex, language), physician specialty (primary care vs. specialist), health plan (lowincome subsidy vs. other), Centers for Medicare \& Medicaid Services (CMS) risk score, Deyo's Charlson Comorbidity Index (CCI),$^{51,52}$ and number of distinct medications.

The CCI is constructed based on ICD-9-CM codes and assigns weights with a range of -1 to 6 for 19 major clinical conditions, depending on their adjusted relative risks. ${ }^{51-53}$ The CMS risk score accounts for medication burden and disease severity and is calculated based on data taken from a large pool of beneficiaries to estimate the average predicted costs for each of the component factors (e.g., age, sex, low-income 


\section{A Pharmacist Telephone Intervention to Identify Adherence Barriers and Improve Adherence Among Nonadherent Patients with Comorbid Hypertension and Diabetes in a Medicare Advantage Plan}

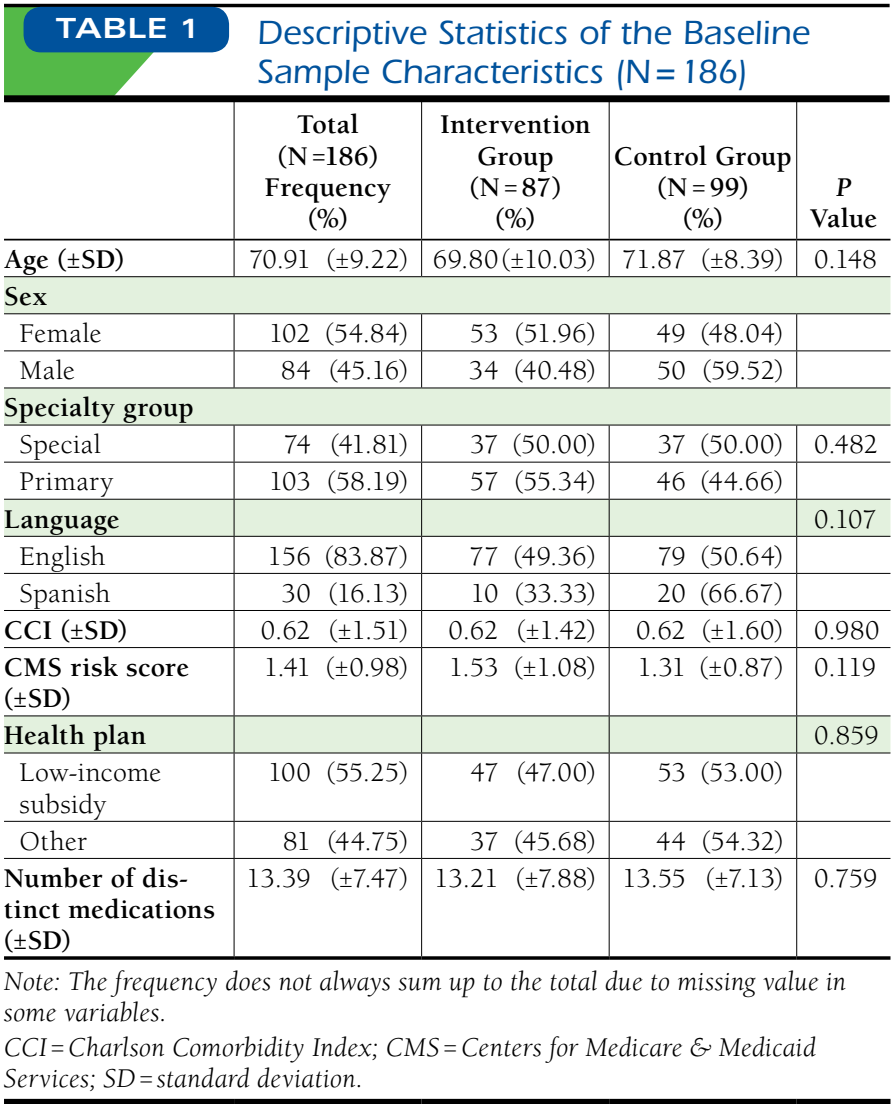

status, individual disease groups). It consists of 189 disease classifications for use in risk adjusting of clinical outcomes in Medicare populations. ${ }^{54,55}$ The CCI and CMS risk score were included as continuous variables with a range of 0-8 and 0.265.13, respectively.

All statistical analyses were performed using SAS software package 9.3 (SAS Institute, Cary, NC) at a priori significance level of 0.05. Sample size estimation was conducted using GPower 3.1 statistical software (Informer Technologies, Walnut, CA). It was estimated that a total of 184 patients would be needed for a two-tail analysis using logistic regression at a 0.05 $\alpha$-level and $0.20 \beta$-level (80\% power), and for a 1.7 odds ratio (OR), and approximately 185 patients would be needed for a multiple linear regression analysis with an effect size of $0.10 .^{56}$

\section{Results}

A total of 391 patients were identified as nonadherent to ACEIs/ ARBs. Of those, 186 had diagnoses of HTN and DM and were included in the study. The descriptive baseline sample characteristics of those 186 patients are presented in Table 1.

Of the 186 patients, 87 had received the pharmacist phone call intervention. The 87 patients receiving the call were randomly selected from the patients who were identified as nonadherent

\begin{tabular}{l|c|c}
\hline \multicolumn{1}{c}{ TABLE 2 } & $\begin{array}{l}\text { Main Barriers Among Patients with } \\
\text { Hypertension and Diabetes Receiving } \\
\text { Phone Call Intervention (N=87) }\end{array}$ \\
\hline Main Barrier & Frequency & Percentage \\
\hline Forgetfulness & 22 & 25.29 \\
\hline Doctor & 15 & 16.79 \\
\hline Adverse event & 6 & 6.90 \\
\hline Cost and alternative source/insurance & 5 & 5.75 \\
\hline Patient perception & 5 & 5.75 \\
\hline Dose reduction & 5 & 5.75 \\
\hline Pharmacy issue & 3 & 3.45 \\
\hline Patient discontinued ${ }^{a}$ & 2 & 2.30 \\
\hline Denial & 2 & 2.30 \\
\hline Lost medication & 1 & 1.15 \\
\hline Interruption (admission) & 1 & 1.15 \\
\hline Transportation & 1 & 1.15 \\
\hline Unknown & 19 & 21.84 \\
\hline Discontinud for uspecified
\end{tabular}

${ }^{a}$ Discontinued for unspecified reason, without the supervision of physician.

during the intervention implementation period. Nonadherent patients who were not contacted $(n=99)$ were considered in the control group. Among these patients, forgetfulness (25.29\%) and doctor issues, such as having difficulty scheduling appointments $(16.79 \%)$, were the most commonly reported barriers, followed by fear of adverse events (AEs) (6.90\%) and cost and alternative alternative source/insurance (5.75\%). The frequency distribution of these adherence barriers is presented in Table 2 . All the $P$ values of chi-square test results were statistically insignificant $(P>0.050)$, which indicated that these barriers did not vary across patients' age, sex, language, income, and prescribers' specialty group. Chi-square analysis results are presented in Table 3.

All 186 patients were continuously enrolled in the health plan and had records in the database, so our attrition rate was 0 . However, 29 patients had switched to other drug classes for treating DM and HTN. After excluding those who switched, 157 patients were included in the logistic regression model. Of those, 131 had continued using ACEIs/ARBs and 26 completely discontinued using ACEIs/ARBs, but they were not switched to another drug class. The baseline sample characteristics of those 157 patients are presented in Table 4 .

The linear regression model included the 131 patients who had prescription refill records of ACEIs or ARBs during the 6-month post-intervention period; 66 were in the intervention group and 65 were in the control group. The baseline sample characteristics of those 131 patients are also presented in Table 4. The mean ( \pm standard deviation $[S D]$ ) post-intervention PDC for the intervention group was $0.58( \pm 0.26)$ and for the control group $0.29( \pm 0.17)$. 


\section{A Pharmacist Telephone Intervention to Identify Adherence Barriers and Improve Adherence Among Nonadherent Patients with Comorbid Hypertension and Diabetes in a Medicare Advantage Plan}

\begin{tabular}{|c|c|c|c|c|}
\hline \multirow[t]{3}{*}{ TAB } & \multicolumn{4}{|c|}{$\begin{array}{l}\text { Chi-square Analyses of Group } \\
\text { Differences Among Patients with } \\
\text { Hypertension and Diabetes Receiving } \\
\text { Phone Call Intervention ( } N=87)\end{array}$} \\
\hline & \multicolumn{3}{|c|}{ Main Barrier } & \multirow[b]{2}{*}{$P$ Value } \\
\hline & Forgetfulness & \begin{tabular}{|c|} 
Other Issues \\
(Cost/ \\
Pharmacy \\
Doctor/Patient \\
Perception/ \\
Denial) \\
\end{tabular} & $\begin{array}{c}\text { Unknown } \\
\text { (Reason Was } \\
\text { Not Reported } \\
\text { by Patients) } \\
\end{array}$ & \\
\hline \multicolumn{5}{|l|}{ Age } \\
\hline $35-65$ & 5 & 13 & 2 & 0.302 \\
\hline$>65$ & 17 & 33 & 17 & \\
\hline \multicolumn{5}{|l|}{ Sex } \\
\hline Male & 11 & 14 & 9 & 0.212 \\
\hline Female & 11 & 32 & 10 & \\
\hline \multicolumn{5}{|c|}{ Specialty group } \\
\hline Special & 9 & 19 & 4 & 0.077 \\
\hline Primary & 11 & 24 & 13 & \\
\hline \multicolumn{5}{|l|}{ Income } \\
\hline Low & 13 & 24 & 10 & 0.858 \\
\hline Other & 9 & 22 & 9 & \\
\hline \multicolumn{5}{|l|}{ Language } \\
\hline English & 18 & 42 & 17 & 0.512 \\
\hline Spanish & 4 & 4 & 2 & \\
\hline
\end{tabular}

Intervention was a significant predictor of better adherence (higher PDC) in the linear regression model after adjusting for all the other baseline covariates $(\beta=0.3182, P<0.001)$. However, the other covariates were not significantly associated with better adherence. In the logistic regression model for predicting medication discontinuation, intervention and comorbidity index were found to be significantly associated with medication discontinuation. Patients who received intervention were more likely to continue using ACEIs/ARBs $(\mathrm{OR}=3.56$, 95\% CI $=1.06-11.86)$. Patients with a higher CCI were less likely to continue using ACEIs/ARBs (OR=0.72, 95\% CI $=0.53$ 0.99). The other covariates were not found to be significantly associated with medication discontinuation. The results of the logistic regression model and the linear regression model are presented in Table 5.

\section{Discussion}

The study examined the influence of a brief pharmacist telephone intervention on identifying adherence barriers as well as on adherence to ACEI/ARB medications among nonadherent patients with comorbid HTN and DM enrolled in a Medicare Advantage plan. In our study, we found the pharmacist telephone intervention resulted in significantly better PDCs during the 6 months following the intervention as well as lower discontinuation rates. Forgetfulness (25.29\%) and doctor issues, such as having difficulty scheduling appointments (16.79\%), were the most commonly reported barriers.
Pharmacists have the knowledge base and expertise needed to provide medication-related education ${ }^{57}$ and are now assuming an important role in chronic illness management. ${ }^{35,58}$ By providing patient education, monitoring medication use, communicating with other health care professionals regarding the patient drug experience, and actively taking steps to prevent medication discontinuation and address compliance issues, pharmacists can be influential in improving adherence, $7,35,59$ as adherence is likely to be higher when patients understand their disease and treatment. ${ }^{60}$

The brief telephone intervention resulted in identifying several adherence barriers among this high-risk population, even though the reason for nonadherence was not reported in approximately $20 \%$ of the 87 patients contacted. The most commonly reported barrier was forgetfulness in approximately a quarter of the 87 nonadherent patients. Forgetfulness has been previously reported as an adherence barrier among elderly patients, ${ }^{61}$ patients with poorly controlled $\mathrm{DM},{ }^{62}$ and underserved patients with DM in Texas. ${ }^{63}$ It is also commonly reported by hypertensive patients. ${ }^{61,64}$ Encouraging patients to relate pill-taking to daily activity and to use pill boxes and organizers, as well as suggesting the use of automated refill reminder programs, could potentially help patients remember to take their medication and improve their adherence.

Approximately 15\% of the patients contacted reported a doctor-related issue, and the pharmacist contacting the physician may help resolve some of these concerns. Other barriers previously reported include cost, ${ }^{61-64}$ side effects, ${ }^{61,63}$ transportation issues, ${ }^{63}$ and hospitalization. ${ }^{63}$ Switching the patients to generic medications when possible and obtaining a 90-day supply may help with cost issues.

Using positive framing when discussing AEs in the context of medication beliefs (most of the patients will not get an AE) may address some of the patient concerns. A commonly reported side effect for patients on ACEIs is a troublesome cough, and switching to an ARB is recommended if that develops. ${ }^{18,65,66}$ Therefore, if a patient complains about a cough, the pharmacist can suggest the switch to an ARB and contact the physician to implement the switch and fill the medication. Suggesting mail delivery can be an option for patients with transportation issues.

Other barriers, such as the patient's perceptions about the disease and treatment, and patient denial of the need for treatment can be a window for the pharmacist to provide patient education and make a difference in the patient's adherence. Pharmacy issues reported should be immediately addressed when possible by the pharmacist contacting the patient's pharmacy. Examples of pharmacy issues identified in this project include the patient waiting for the prescription to be transferred or the patient not receiving the medication because a pharmacist suspects a potential interaction with another medication taken by the patient. 


\section{A Pharmacist Telephone Intervention to Identify Adherence Barriers and Improve Adherence Among Nonadherent Patients with Comorbid Hypertension and Diabetes in a Medicare Advantage Plan}

TABLE 4 Descriptive Statistics of Patients Included in the Linear and Logistic Regression Models

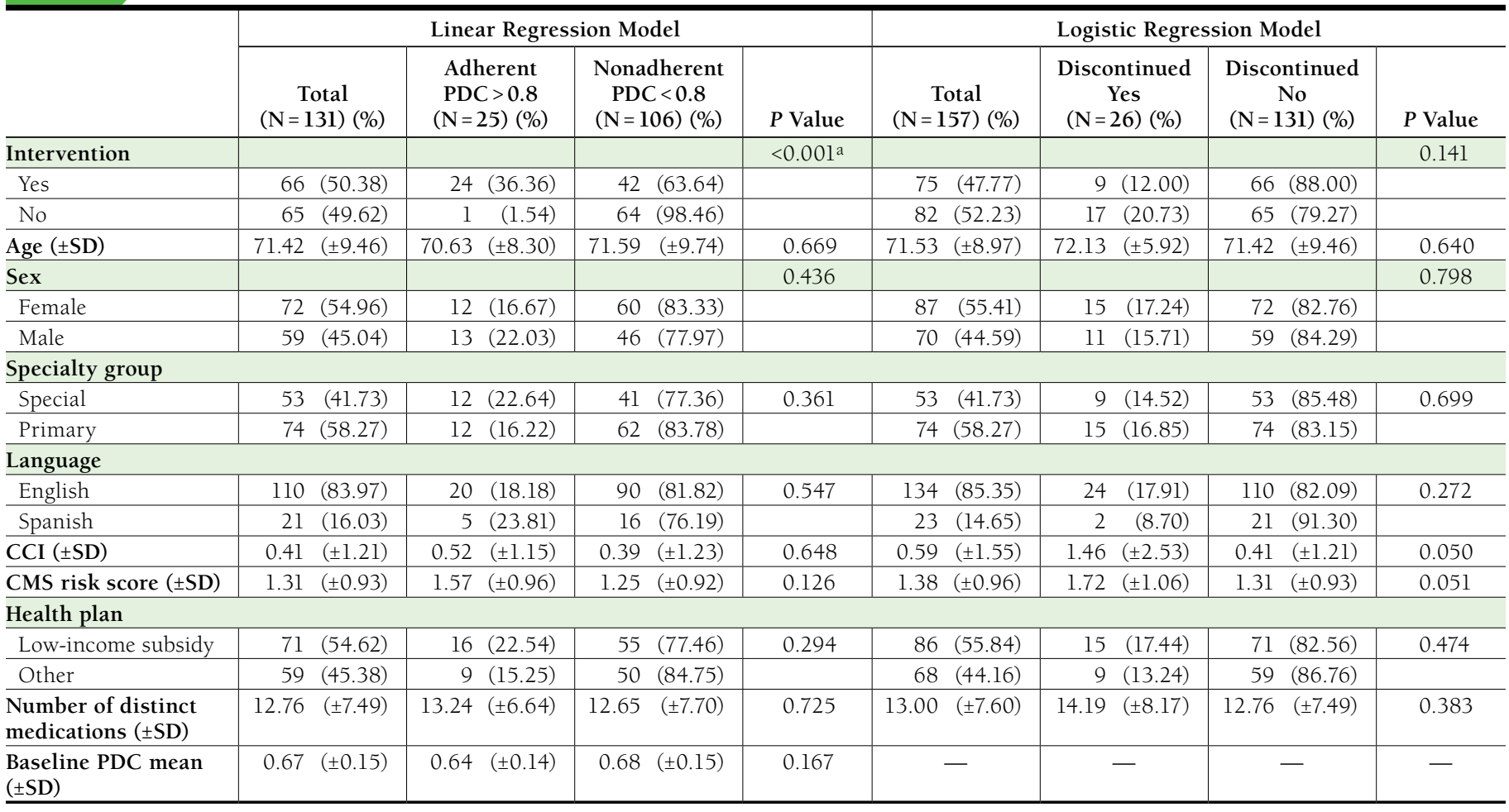

Note: The frequency does not always sum up to total due to missing value in some variables.

andicates significant finding.

$C C I=$ Charlson Comorbidity Index; CMS = Centers for Medicare $\&$ Medicaid Services; PDC = proportion of days covered; SD = standard deviation.

The findings also indicate that the brief telephone intervention resulted in significantly better PDCs during the 6 months following the intervention and lower discontinuation rates among the intervention group compared with the control group. The overall 6-month PDC following the intervention was still low (58\%), given that $80 \%$ adherence is generally considered acceptable., ${ }^{5,24}$

Improving adherence to a clinically meaningful value may require more than a short phone call, especially because we want the behavioral change of improved adherence to be sustained. The transtheoretical model (TTM) of behavioral change recognizes that changing behavior involves progression through several stages as described in the stage-based models of behavior change, ${ }^{67-69}$ and benefits of TTM-based interventions among DM patients at various stages of readiness have been demonstrated. ${ }^{70}$

Literature demonstrates that motivational interviewing (MI) is a promising form of intervention to aid in chronic illness care and promote self-management behaviors such as medication adherence. ${ }^{71} \mathrm{MI}$ is a patient-centered form of guiding to explore ambivalence as well as elicit and strengthen motivation to change $\mathrm{e}^{72,73}$ and is well suited for delivery by phone. ${ }^{71}$
MI fosters behavior change by contrasting the current behavior (medication adherence) to a desired goal (self-care, improved quality of life) as well as promoting self-efficacy in a way that is supportive, collaborative, empathetic, and evocative. ${ }^{71}$ As patients may be at different stages of behavioral change or willingness to change, the counseling is based on the patients' readiness and behavioral stage to minimize resistance and maximize engagement, ${ }^{71}$ in combination with setting target goals and resolving problems to build the patients' confidence in their ability to change. ${ }^{74} \mathrm{MI}$ is a way to help patients recognize their problem and empower them to do something about it, using strategies that are more persuasive than coercive or argumentative. ${ }^{75}$

Future studies incorporating MI techniques to address patient adherence barriers coupled with follow-up calls to guide the patients may be more influential in improving medication adherence among high-risk patients with combined HTN and DM. MI has been used to promote behavioral changes in drug addiction, alcohol abuse, weight loss, and smoking cessation. ${ }^{75}$ It has been shown to improve self-care for DM patient ${ }^{73,76}$ and enhance medication adherence among patients with several chronic illnesses, including HTN, ${ }^{77}$ asthma, ${ }^{78}$ and human immunodeficiency virus. ${ }^{79}$ 


\section{A Pharmacist Telephone Intervention to Identify Adherence Barriers and Improve Adherence Among Nonadherent Patients with Comorbid Hypertension and Diabetes in a Medicare Advantage Plan}

TABLE 5 Results of Linear Regression Model and Logistic Regression Models

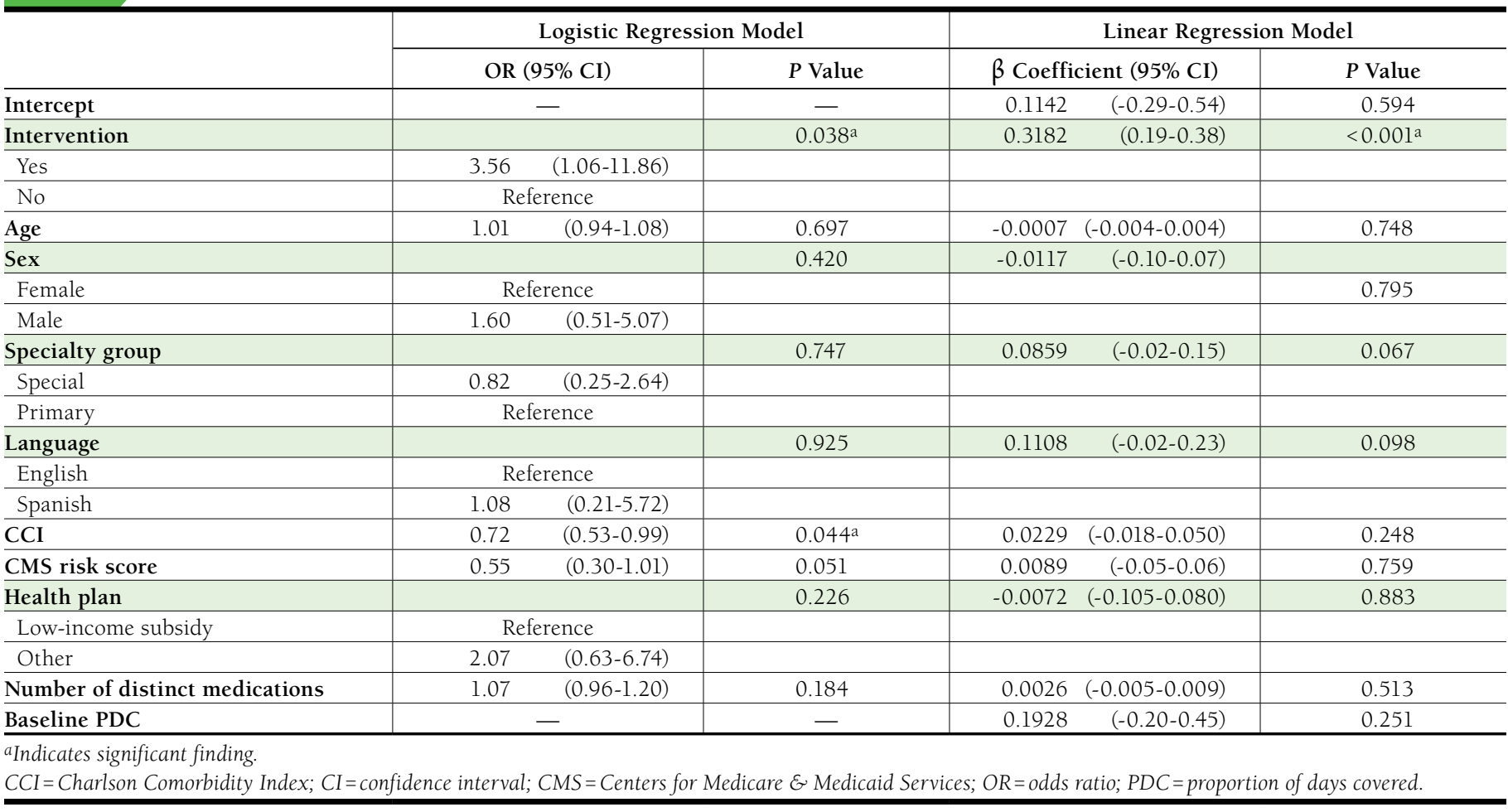

The associations between comorbidity and medication adherence have been variable in previous literature. ${ }^{53,80-82}$ In this study, CMS risk scores were not associated with ACEI/ ARB discontinuation or PDC levels following the intervention. Patients with higher CCI scores were more likely to discontinue their ACEIs/ARBs, possibly due to increased regimen complexity with more comorbidities. ${ }^{83}$

\section{Limitations}

Several limitations to this study can be described. Filling the prescription does not guarantee the patient took the medication, but prescription refill rates are a relatively accurate measure of overall adherence. ${ }^{2,5}$ We were unable to capture prescriptions that were filled from pharmacies outside the network or paid by cash. We were unable to ascertain if the ACEIs/ARBs were prescribed for HTN and DM or other medical conditions using the claims data. The patients had diagnosis records of both DM and HTN and had prescription fill records of ACEIs/ARBs, so we assumed these medications were prescribed for DM and HTN. We were also unable to identify whether patients had a primary diagnosis of DM and a secondary diagnosis of HTN or vice versa, which is another limitation of the claims database.
Other limitations include lack of comprehensive clinical data and information on potential confounders like race, side effects, low health literacy, and perceived health. Randomization in future studies can help overcome some of these limitations. We also could not account for use of samples or hospitalizations during a follow-up period.

\section{Conclusions}

This study demonstrated that the brief pharmacist telephone intervention resulted in significantly better PDCs during the 6 months following the intervention and lower discontinuation rates in a group of nonadherent patients with comorbid HTN and DM. The overall PDC rates in both the intervention and control groups were still lower than the recommended $80 \%$. Improving adherence to clinically meaningful values may require more than a brief pharmacist phone call. Incorporating MI techniques with follow-up calls to address adherence barriers may be more influential in forming sustainable behavioral change and enhancing medication adherence.

While the cost of such adherence improvement programs may be somewhat high given the pharmacist time needed, significant savings can be reflected in less physician and emergency room visits and decreased hospitalization of high-risk patients. Such savings may prove cost-effective to health plans and the health care system as a whole. 


\section{A Pharmacist Telephone Intervention to Identify Adherence Barriers and Improve Adherence Among Nonadherent Patients with Comorbid Hypertension and Diabetes in a Medicare Advantage Plan}

\section{Authors}

SUSAN M. ABUGHOSH, PhD, is Assistant Professor; XIN WANG, MS, is a Graduate Student; EKERE JAMES ESSIEN, MD, DrPh, is Professor; and MARC FLEMING, PhD, is Assistant Professor, Department of Pharmaceutical Health Outcomes and Policy, University of Houston College of Pharmacy, Houston, Texas. OMAR SERNA, PharmD, BCACP, is Clinical Operations Director, and CHRIS HENGES, PharmD, is Pharmacy Resident, CignaHealthSpring, Houston, Texas. SANTHI MASILAMANI, PharmD, CDE, MBA, is Clinical Assistant Professor, and NANCY CHUNG, PharmD, BCACP, is Clinical Assistant Professor, Department of Pharmacy Practice and Translational Research, University of Houston College of Pharmacy, Houston, Texas.

AUTHOR CORRESPONDENCE: Susan M. Abughosh, PhD, Department of Pharmaceutical Health Outcomes and Policy, University of Houston College of Pharmacy, 1441 Moursund St., Houston, TX 77030. Tel.: 832.842.8395; Fax: 832.842.8383;

E-mail:smabugho@central.uh.edu.

\section{DISCLOSURES}

No outside funding supported this study. The authors declare no conflicts of interest.

Study design was created primarily by Abughosh and Fleming, with help from the rest of the authors. Abughosh, Serna, Henges, and Masilamani collected the data, with data interpretation performed by Wang, Essien, Chung, and Abughosh, assisted by Fleming. The manuscript was written by Abughosh, along with Wang and assisted by Serna, Fleming, and Essien. Abughosh and Wang took the lead in manuscript revision, with assistance from the other authors.

\section{REFERENCES}

1. Butler RJ, Davis TK, Johnson WG, Gardner HH. Effects of nonadherence with prescription drugs among older adults. Am J Manag Care. 2011;17(2):153-60

2. MacLaughlin EJ, Raehl CL, Treadway AK, Sterling TL, Zoller DP, Bond CA Assessing medication adherence in the elderly: which tools to use in clinical practice? Drugs Aging. 2005;22(3):231-55.

3. Foreman KF, Stockl KM, Le LB, et al. Impact of a text messaging pilot program on patient medication adherence. Clin Ther. 2012;34(5):1084-91.

4. Van der Wal MH, Jaarsma T. Adherence in heart failure in the elderly: problem and possible solutions. Int J Cardiol. 2008;125(2):203-08.

5. Osterberg L, Blaschke T. Adherence to medication. N Engl J Med. 2005;353(5):487-97.

6. Kripalani S, Yao X, Haynes RB. Interventions to enhance medication adherence in chronic medical conditions: a systematic review. Arch Intern Med. 2007;167(6):540-50.

7. Murray MD, Morrow DG, Weiner M, et al. A conceptual framework to study medication adherence in older adults. Am J Geriatr Pharmacother. 2004;2(1):36-43

8. The Henry J. Kaiser Family Foundation. The Medicare Part D Prescription Drug Benefit. October 13, 2015. Available at: http://kff.org/medicare/factsheet/the-medicare-prescription-drug-benefit-fact-sheet/. Accessed Assessed October 13, 2015.

9. Deedwania PC. Blood pressure control in diabetes mellitus: is lower always better, and how low should it go? Circulation. 2011;123(24):2776-78.

10. Deedwania PC. Diabetes and hypertension, the deadly duet: importance, therapeutic strategy, and selection of drug therapy. Cardiol Clin. 2005;23(2):139-52

11. Putnam W, Lawson B, Buhariwalla F, et al. Hypertension and type 2 diabetes: what family physicians can do to improve control of blood pressure-an observational study. BMC Fam Pract. 2011;12:86.

12. Tight blood pressure control and risk of macrovascular and microvascular complications in type 2 diabetes: UKPDS 38. UK Prospective Diabetes Study Group. BMJ. 1998;317(7160):703-13.

13. McLean DL, Simpson SH, McAlister FA, Tsuyuki RT. Treatment and blood pressure control in 47,964 people with diabetes and hypertension: a systematic review of observational studies. Can J Cardiol. 2006;22(10):855-60.

14. Bakris GL. A practical approach to achieving recommended blood pressure goals in diabetic patients. Arch Intern Med. 2001;161(22):2661-67.

15. Sowers JR, Epstein M, Frohlich ED. Diabetes, hypertension, and cardiovascular disease: an update. Hypertension. 2001;37(4):1053-59.

16. Natarajan N, Putnam W, Van Aarsen K, Beverley Lawson K, Burge F. Adherence to antihypertensive medications among family practice patients with diabetes mellitus and hypertension. Can Fam Physician. 2013;59(2):e93-100.

17. American Diabetes Association. Standards of medical care in diabetes-2015. Diabetes Care. 2015;38(Suppl. 1):S1-94. Available at: http://professional.diabetes.org/admin/UserFiles/0\%20-\%20Sean/Documents/January\%20 Supplement\%20Combined_Final.pdf. Accessed November 13, 2015.

18. Cooke CE, Fatodu H. Physician conformity and patient adherence to ACE inhibitors and ARBs in patients with diabetes, with and without renal disease and hypertension, in a Medicaid managed care organization. J Manag Care Pharm. 2006;12(8):649-55. Available at: http://amcp.org/data/ jmcp/649-655.pdf.

19. Lopez-Jaramillo P, Lopez-Lopez J, Lopez-Lopez C, Rodriguez-Alvarez MI. The goal of blood pressure in the hypertensive patient with diabetes is defined: now the challenge is go from recommendations to practice. Diabetol Metab Syndr. 2014;6(1):31.

20. Effects of ramipril on cardiovascular and microvascular outcomes in people with diabetes mellitus: results of the HOPE study and MICROHOPE substudy. Heart Outcomes Prevention Evaluation Study Investigators. Lancet. 2000;355(9200):253-59.

21. Yusuf S, Sleight P, Pogue J, Bosch J, Davies R, Dagenais G. Effects of an angiotensin-converting-enzyme inhibitor, ramipril, on cardiovascular events in high-risk patients. The Heart Outcomes Prevention Evaluation Study Investigators. N Engl J Med. 2000;342(3):145-53.

22. Estacio RO, Jeffers BW, Hiatt WR, Biggerstaff SL, Gifford N, Schrier RW. The effect of nisoldipine as compared with enalapril on cardiovascular outcomes in patients with non-insulin-dependent diabetes and hypertension. N Engl J Med. 1998;338(10):645-52.

23. Schmittdiel JA, Uratsu CS, Karter AJ, et al. Why don't diabetes patients achieve recommended risk factor targets? Poor adherence versus lack of treatment intensification. J Gen Intern Med. 2008;23(5):588-94.

24. Ho PM, Rumsfeld JS, Masoudi FA, et al. Effect of medication nonadherence on hospitalization and mortality among patients with diabetes mellitus. Arch Intern Med. 2006;166(17):1836-41.

25. Grant RW, Devita NG, Singer DE, Meigs JB. Polypharmacy and medication adherence in patients with type 2 diabetes. Diabetes Care. 2003;26(5):1408-12.

26. Brown LC, Johnson JA, Majumdar SR, Tsuyuki RT, McAlister FA. Evidence of suboptimal management of cardiovascular risk in patients with type 2 diabetes mellitus and symptomatic atherosclerosis. CMAJ. 2004;171(10):1189-92.

27. Kettani FZ, Dragomir A, Côté R, et al. Impact of a better adherence to antihypertensive agents on cerebrovascular disease for primary prevention. Stroke. 2009:40(1):213-20. 


\section{A Pharmacist Telephone Intervention to Identify Adherence Barriers and Improve Adherence Among Nonadherent Patients with Comorbid Hypertension and Diabetes in a Medicare Advantage Plan}

28. Mazzaglia G, Ambrosioni E, Alacqua M, et al. Adherence to antihypertensive medications and cardiovascular morbidity among newly diagnosed hypertensive patients. Circulation. 2009;120(16):1598-605.

29. Degli Esposti L, Saragoni S, Benemei S, et al. Adherence to antihypertensive medications and health outcomes among newly treated hypertensive patients. Clinicoecon Outcomes Res. 2011;3:47-54.

30. Piette JD, Weinberger M, Kraemer FB, McPhee SJ. Impact of automated calls with nurse follow-up on diabetes treatment outcomes in a Department of Veterans Affairs Health Care System: a randomized controlled trial. Diabetes Care. 2001;24(2):202-08

31. Walker EA, Shmukler C, Ullman R, Blanco E, Scollan-Koliopoulus M, Cohen HW. Results of a successful telephonic intervention to improve diabetes control in urban adults: a randomized trial. Diabetes Care. 2011;34(1):2-7.

32. Wolever RQ, Dreusicke M, Fikkan J, et al. Integrative health coaching for patients with type 2 diabetes: a randomized clinical trial. Diabetes Educ. 2010;36(4):629-39.

33. Walker EA, Schechter CB, Caban A, Basch CE. Telephone intervention to promote diabetic retinopathy screening among the urban poor. Am J Prev Med. 2008;34(3):185-91.

34. Moore JM, Shartle D, Faudskar L, Matlin OS, Brennan TA. Impact of a patient-centered pharmacy program and intervention in a high-risk group. J Manag Care Pharm. 2013;19(3):228-36. Available at: http://www.amcp.org/ WorkArea/DownloadAsset.aspx?id=16313.

35. Lindenmeyer A, Hearnshaw H, Vermeire E, Van Royen P, Wens J, Biot Y. Interventions to improve adherence to medication in people with type 2 diabetes mellitus: a review of the literature on the role of pharmacists. J Clin Pharm Ther. 2006;31(5):409-19.

36. Brennan TA, Dollear TJ, Hu M, et al. An integrated pharmacy-based program improved medication prescription and adherence rates in diabetes patients. Health Aff (Millwood). 2012;31(1):120-29.

37. Odegard PS, Carpinito G, Christensen DB. Medication adherence program: adherence challenges and interventions in type 2 diabetes. J Am Pharm Assoc (2003). 2013;53(3):267-72.

38. Odegard PS, Christensen DB. MAP study: RCT of a medication adherence program for patients with type 2 diabetes. J Am Pharm Assoc (2003). 2012;52(6):753-62.

39. Morgado M, Rolo S, Castelo-Branco M. Pharmacist intervention program to enhance hypertension control: a randomised controlled trial. Int J Clin Pharm. 2011;33(1):132-40

40. Fikri-Benbrahim N, Faus MJ, Martinez-Martinez F, Sabater-Hernández D. Impact of a community pharmacists' hypertension-care service on medication adherence. The AFenPA study. Res Social Adm Pharm. 2013;9(6):797-805.

41. Lee JK, Grace KA, Taylor AJ. Effect of a pharmacy care program on medication adherence and persistence, blood pressure, and low-density lipoprotein cholesterol: a randomized controlled trial. JAMA. 2006;296(21):2563-71.

42. Lau R, Stewart K, McNamara KP, et al. Evaluation of a community pharmacy-based intervention for improving patient adherence to antihypertensives: a randomised controlled trial. BMC Health Serv Res. 2010;10:34.

43. Svarstad BL, Kotchen JM, Shireman TI, et al. Improving refill adherence and hypertension control in black patients: Wisconsin TEAM trial. J Am Pharm Assoc (2003). 2013;53(5):520-29.

44. Lowe CJ, Raynor DK, Purvis J, Farrin A, Hudson J. Effects of a medicine review and education programme for older people in general practice. Br J Clin Pharmacol. 2000;50(2):172-75.

45. McLean DL, McAlister FA, Johnson JA, et al. A randomized trial of the effect of community pharmacist and nurse care on improving blood pressure management in patients with diabetes mellitus: study of cardiovascular risk intervention by pharmacists-hypertension (SCRIP-HTN). Arch Intern Med. 2008;168(21):2355-61
46. Planas LG, Crosby KM, Mitchell KD, Farmer KC. Evaluation of a hypertension medication therapy management program in patients with diabetes. J Am Pharm Assoc (2003). 2009;49(2):164-70.

47. Santschi V, Chiolero A, Burnand B, Colosimo AL, Paradis G. Impact of pharmacist care in the management of cardiovascular disease risk factors: a systematic review and meta-analysis of randomized trials. Arch Intern Med. 2011;171(16):1441-53.

48. Santschi V, Chiolero A, Paradis G, Colosimo AL, Burnand B. Pharmacist interventions to improve cardiovascular disease risk factors in diabetes: a systematic review and meta-analysis of randomized controlled trials. Diabetes Care. 2012;35(12):2706-17.

49. Peterson AM, Nau DP, Cramer JA, Benner J, Gwadry-Sridhar F, Nichol M. A checklist for medication compliance and persistence studies using retrospective databases. Value Health. 2007;10(1):3-12.

50. Hess LM, Raebel MA, Conner DA, Malone DC. Measurement of adherence in pharmacy administrative databases: a proposal for standard definitions and preferred measures. Ann Pharmacother. 2006;40(7-8):1280-88.

51. Charlson ME, Pompei P, Ales KL, MacKenzie CR. A new method of classifying prognostic comorbidity in longitudinal studies: development and validation. J Chronic Dis. 1987;40(5):373-83.

52. Deyo RA, Cherkin DC, Ciol MA. Adapting a clinical comorbidity index for use with ICD-9-CM administrative databases. J Clin Epidemiol. 1992;45(6):613-19.

53. Yang Y, Thumula V, Pace PF, Banahan BF 3rd, Wilkin NE, Lobb WB. Predictors of medication nonadherence among patients with diabetes in Medicare Part D programs: a retrospective cohort study. Clin Ther. 2009;31(10):2178-88; discussion 2150-51

54. Parikh NM, Morgan RO, Kunik ME, et al. Risk factors for dementia in patients over 65 with diabetes. Int J Geriatr Psychiatry. 2011;26(7):749-57.

55. Johnson ML, Parikh N, Kunik ME, et al. Antihypertensive drug use and the risk of dementia in patients with diabetes mellitus. Alzheimers Dement. 2012;8(5):437-44

56. Faul F, Erdfelder E, Lang AG, Buchner A. G*Power 3: a flexible statistical power analysis program for the social, behavioral, and biomedical sciences. Behav Res Methods. 2007;39(2):175-91.

57. Szkiladz A, Carey K, Ackerbauer K, Heelon M, Friderici J, Kopcza K. Impact of pharmacy student and resident-led discharge counseling on heart failure patients. J Pharm Pract. 2013;26(6):574-79.

58. ASHP statement on the pharmacist's role in primary care. Am J Health Syst Pharm. 1999;56(16):1665-67.

59. Rybacki JJ. Improving cardiovascular health in postmenopausal women by addressing medication adherence issues. J Am Pharm Assoc (Wash). 2002;42(1):63-71; quiz 72-73.

60. Varma S, McElnay JC, Hughes CM, Passmore AP, Varma M.

Pharmaceutical care of patients with congestive heart failure: interventions and outcomes. Pharmacotherapy. 1999;19(7):860-69.

61. Krousel-Wood M, Muntner P, Islam T, Morisky DE, Webber LS. Barriers to and determinants of medication adherence in hypertension management: perspective of the cohort study of medication adherence among older adults. Med Clin North Am. 2009;93(3):753-69.

62. Odegard PS, Gray SL. Barriers to medication adherence in poorly controlled diabetes mellitus. Diabetes Educ. 2008;34(4):692-97.

63. Bailey GR, Barner JC, Weems JK, et al. Assessing barriers to medication adherence in underserved patients with diabetes in Texas. Diabetes Educ. 2012;38(2):271-79.

64. Okwuonu CG, Ojimadu NE, Okaka EI, Akemokwe FM. Patient-related barriers to hypertension control in a Nigerian population. Int J Gen Med. 2014;7:345-53.

65. Spinar J, Vitovec J, Soucek M, Dusek L, Pavlik T, CORD Investigators. CORD: COmparsion of Recommended Doses of ACE inhibitors and angiotensin II receptor blockers. Vnitr Lek. 2009;55(5):481-88. 


\section{A Pharmacist Telephone Intervention to Identify Adherence Barriers and Improve Adherence Among Nonadherent Patients with Comorbid Hypertension and Diabetes in a Medicare Advantage Plan}

66. Barreras A, Gurk-Turner C. Angiotensin II receptor blockers. Proc (Bayl Univ Med Cent). 2003;16(1):123-26.

67. Prochaska JO, DiClemente CC. Stages and processes of self-change of smoking: toward an integrative model of change. J Consult Clin Psychol. 1983:51(3):390-95

68. Prochaska JO, DiClemente CC, Norcross JC. In search of how people change. Applications to addictive behaviors. Am Psychol. 1992;47(9):1102-14.

69. DiClemente CC, Prochaska JO, Fairhurst SK, Velicer WF, Velasquez MM, Rossi JS. The process of smoking cessation: an analysis of precontemplation, contemplation, and preparation stages of change. J Consult Clin Psychol. 1991;59(2):295-304

70. Jones H, Edwards L, Vallis TM, et al. Changes in diabetes self-care behaviors make a difference in glycemic control: the Diabetes Stages of Change (DiSC) study. Diabetes Care. 2003;26(3):732-37.

71. Turner AP, Sloan AP, Kivlahan DR, Haselkorn JK. Telephone counseling and home telehealth monitoring to improve medication adherence: results of a pilot trial among individuals with multiple sclerosis. Rehabil Psychol. 2014;59(2):136-46.

72. Miller WR, Rollnick S. Ten things that motivational interviewing is not. Behav Cogn Psychother. 2009;37(2):129-40.

73. Christie D, Channon S. The potential for motivational interviewing to improve outcomes in the management of diabetes and obesity in paediatric and adult populations: a clinical review. Diabetes Obes Metab. 2014;16(5):381-87.

74. Gance-Cleveland B. Motivational interviewing: improving patient education. J Pediatr Health Care. 2007;21(2):81-88.
75. Rubak S, Sandbaek A, Lauritzen T, Christensen B. Motivational interviewing: a systematic review and meta-analysis. Br J Gen Pract. 2005;55(513):305-12

76. Hawkins SY. Improving glycemic control in older adults using a videophone motivational diabetes self-management intervention. Res Theory Nurs Pract. 2010;24(4):217-32.

77. Ogedegbe G, Chaplin W, Schoenthaler A, et al. A practice-based trial of motivational interviewing and adherence in hypertensive African Americans. Am J Hypertens. 2008;21(10):1137-43.

78. Halterman JS, Szilagyi PG, Fisher SG, et al. Randomized controlled trial to improve care for urban children with asthma: results of the School-Based Asthma Therapy trial. Arch Pediatr Adolesc Med. 2011;165(3):262-68.

79. Dilorio C, McCarty F, Resnicow K, et al. Using motivational interviewing to promote adherence to antiretroviral medications: a randomized controlled study. AIDS Care. 2008;20(3):273-83.

80. Bailey JE, Hajjar M, Shoib B, Tang J, Ray MM, Wan JY. Risk factors associated with antihypertensive medication nonadherence in a statewide Medicaid population. Am J Med Sci. 2014;348(5):410-15.

81. Chapman RH, Petrilla AA, Benner JS, Schwartz JS, Tang SS. Predictors of adherence to concomitant antihypertensive and lipid-lowering medications in older adults: a retrospective, cohort study. Drugs Aging. 2008;25(10):885-92

82. Lagu T, Weiner MG, Eachus S, Tang SS, Schwartz JS, Turner BJ. Effect of patient comorbidities on filling of antihypertensive prescriptions. Am J Manag Care. 2009;15(1):24-30.

83. Garcia-Pérez LE, Alvarez M, Dilla T, Gil-Guillén V, Orozco-Beltrán D. Adherence to therapies in patients with type 2 diabetes. Diabetes Ther. 2013;4(2):175-94 


\section{A Pharmacist Telephone Intervention to Identify Adherence Barriers and Improve Adherence Among Nonadherent Patients with Comorbid Hypertension and Diabetes in a Medicare Advantage Plan}

\section{APPENDIX Medication Adherence Call (for Nonadherent Members)}

Member Information

Name (last, first):

Date:

\begin{tabular}{l|l|l}
\hline DOB: & Age: & Sex: M F \\
\hline
\end{tabular}

Part D STARS Adherence Measures

\begin{tabular}{lllll}
\hline Nonadherent measures: & DM & HTN & Statin & \\
\hline PDC of nonadherent measures: & DM & HTN & Statin
\end{tabular}

Nonadherent measures:

Last fill date:

Days since last fill:

Hello, my name is $<$ Your Name $>$ and I am a pharmacist/pharmacy intern calling from Cigna-HealthSpring, your health insurance company. The specific medication(s) I am speaking about is/are: <medication name $>$.

The reason for this call is to see if there is anything I can assist you with in order to ensure that you receive this/these medication(s).

I am contacting you because I have taken a look at your pharmacy claims information and have noticed that you have not picked up certain medication(s).

Please let me know what, if anything, has caused you difficulty in picking up this/these medication(s). Possible reasons could include:

\begin{tabular}{l|l|l|l}
\hline Cost & $\begin{array}{l}\text { Adverse effects } \\
\text { (experienced or potential) }\end{array}$ & Transportation issues & Forgetfulness \\
\hline $\begin{array}{l}\text { Interruption } \\
\text { (ex.: hospitalization, travel) }\end{array}$ & $\begin{array}{l}\text { Receiving samples/receiving patient } \\
\text { assistance }\end{array}$ & $\begin{array}{l}\text { Does not feel medication is } \\
\text { necessary }\end{array}$ & Out of refills \\
\hline $\begin{array}{l}\text { Reduction of dose } \\
(\text { ex.: } 2 \text { pills } \rightarrow 1 \text { pill })\end{array}$ & No longer sees prescribing MD & Discontinuation by MD & \\
\hline
\end{tabular}

Other:

Thank you for addressing this issue with me. Based on your concerns, here are some recommendations I have for you in order to ensure that you are able to take your medications.

1)

2)

3)

Thank you for your time. 